\title{
WOMEN SAFETY DEVICE BASED ON GPS \& GSM
}

\author{
Dr. Shuchi Dave \\ Associate Professor, Mathematics \\ Poornima College of Engineering, \\ Jaipur (Rajasthan), India
}

\begin{abstract}
The number of Smartphone users is increasing day by day all over the world. A Smartphone has many applications that are useful to people. Security for women has become a major issue in India. From the last ten years, the statistics among women abuse, sexual harassment have been steadily increasing. It has become mandatory to come up with a solution to protect the women from being a victim and to reduce the attacks. The main objective of this paper is to design and implement a highly reliable system for protecting women from being harassed. In this paper, we have developed a personal safety product which is wearable also to keep women safe $24 / 7$.
\end{abstract}

Keywords; Women Safety Device Circuit, RFID, GPS, Microcontroller, GSM, Raspberry Pi with Python

\section{INTRODUCTION}

Women' security in India has become a concerning issue since 2012. Crimes like abducting, cruel behaviour towards women and little youngsters have arrived at unimaginable levels. The National Crime Records Bureau (NCRB), 2015 has announced that the conviction pace of violations against women in India is fewer than $22 \%$ [1] . The instances of wrongdoing against women have totaled to 327,394, as announced in 2015. The current insights show 3.1\% decay from 2014 [1,2] The most elevated conviction rate that has ever been accounted for was under the Immoral Traffic Prevention Act (49\%). It was trailed by the Protection of Women from Domestic Violence Act (47.8\%). Abetment to suicide and Cruelty by Husband and his relatives was accounted for to have the least conviction rate[15]. As per the above figure, wrongdoing against women has expanded each year. From 2012 to 2013, the cases expanded from $2,44,270$ to $3.09,546[2]$. The cases expanded from 2013 to 2014 and afterward diminished marginally in 2015. The conviction rate was expanded distinctly by $0.7 \%$ from 2014 to 2015 . The gadget proposed in this paper guarantee youngster security The women security gadget is a wearable gadget through which guardians can monitor their youngsters. The proposed gadget will fill in as a crisis gadget for women in trouble. This

\author{
Vikash Singh, Vishnu Singh, Vishnu Kumawat \\ B.Tech, EC \\ Poornima College of Engineering, \\ Jaipur (Rajasthan), India
}

is a smart women safety system using Radio Frequency Identification (RFID) and Global positioning system (GPS) [3]. It is packed with features for both everyday safety and real emergencies. This device will provide the fastest and simplest way to get the nearest help. Women have to do a single click and all features of this device start functioning. the main idea here is using an active RFID tag with a passive RFID reader to scan the information and this information is transferred to the microcontroller. Once the information is received by the controller, it sends the message to the contacts through the GSM module and the location is tracked through the GPS. We are using programming on Raspberry Pi with Python. This paper also summarizes other significant works in this field and hence forth discussed our device in a greater detail. The two primary equipment parts of this gadget is an Arduino Uno microcontroller and a GSM module.

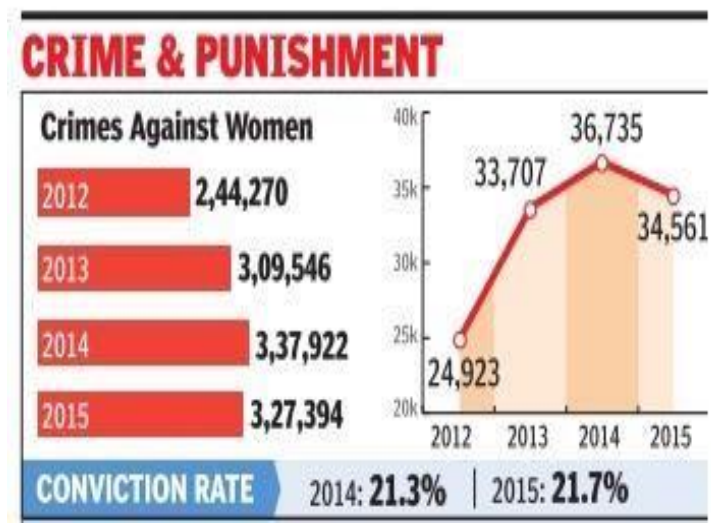

Fig 1. Crime against women statistics

GSM represents Global System for portable Communications. The innovation behind the Global System for Mobile correspondence $\left(\right.$ GSM $\left.^{\mathrm{TM}}\right)$ utilizes balance of Phase Shift Keying (PSK) which is a variation of Gaussian Minimum Shift Keying (GMSK) with Time Division Multiple Access (TDMA) motioning over Frequency Division Duplex (FDD) bearers. GSM was structured chiefly for voice communication, yet a scope of conveyor administrations were characterized like ISDN, permitting circuit exchanged information associations up to 9600 
information bits/s. General Packet Radio Service (GPRS) was built up a couple of years after the fact permitting bundle changed applications consequently empowering access to web and combination of numerous bearers for higher speed. The GPRS contributions were monetarily presented first in the mid 2000's .Arduino is a stage on which mix of equipment and programming is actualized. It offers a progression of simple and advanced data sources. [5]. the improvement condition is unreservedly accessible for all stages and is effectively programmable. Nature is additionally exceptionally adaptable. The GSM module utilized for the gadget is a SIM808 module. It is profoundly perfect with ATmega 328p microcontroller. The gadget is enacted by the women in trouble by squeezing a signal for an emergency response. The signal for an emergency response initiates the GSM module for correspondence. The module comprises of a normal SIM card which will be utilized for calling and SMS purposes. The module will send the directions of the women to the put away portable numbers in the gadget. The idea driving the gadget is additionally to present a costproductive gadget. The gadget ought to be moderate by the normal customer. As far India is concerned, an increasingly intricate answer for the issue would not be prudent in the present time, as it builds the expense of the gadget immensely. The normal Indian shopper won't have the option to bear the cost of or put resources into it. Majority of casualties are underneath or on the destitution line. In this way actualizing the examined gadget can be practical for the normal Indian buyer.

\section{HARDWARE ARCHITECTURE}

The following are the hardware components of the device:

\section{A. Arduino Uno:}

The microcontroller utilized is an ATmega 328p microcontroller. It is a solitary chip microcontroller of the megaAVR family. The [6] microcontroller can be isolated into two sections equipment and programming. The equipment comprises of the accompanying highlights the USB plug which is utilized to transfer the program into the board. It can likewise be utilized as a wellspring of intensity supply. The fitting supplies a controlled voltage of $5 \mathrm{~V}$. On the off chance that it is inadequate, an outer force supply of 9 to $12 \mathrm{~V}$ can be given. There are 5 simple pins (A0 to A5). The advanced I/o pins are from 2 to 13. The reset button is utilized to reset the microcontroller so as to run a new program. There are $3.3 \mathrm{~V}$ and $5 \mathrm{~V}$ power pins to control the Arduino. The subsequent part is the product. The product includes sending orders and directions to speak with and run the equipment. The product condition used to run Arduino is the Arduino segments under IDE are-message window territory, order region and content region. The order territory comprises the menu of apparatuses like File, Edit, Sketch, Tools and Help. The projects can be spared by tapping on the Save button. The content region is the space to compose the code. Installed $\mathrm{C}$ language is the most well-known language used to build up the code or program. As a matter of course there is an arrangement work which is utilized to instate factors. There is likewise a circle subroutine present to include the primary code in it. The message window region is utilized to show the condition of the execution of the program. IDE (Integrated Development Environment).

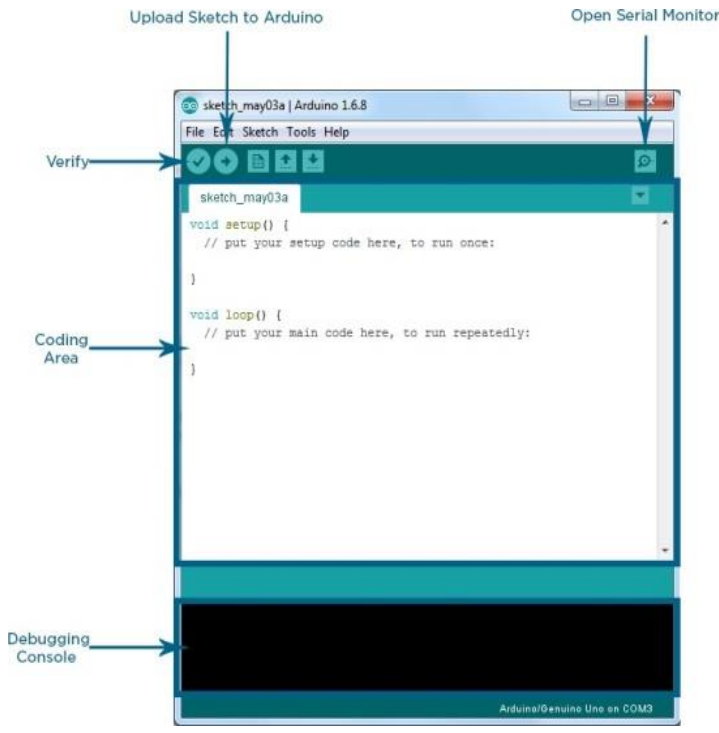

Fig 2. IDE window

\section{B. GSM module:}

The GSM module utilized is a [8] SIM808 module. It is a GSM/GPRS module with quad band which performs satellite correspondence utilizing GPS innovation. Both GPRS and GPS are coordinated into a smaller SMT bundle along these lines sparing both time and cost for clients utilizing the module to create applications. It includes an industry-standard interface and that permits the following of variable assets at any area consistently.

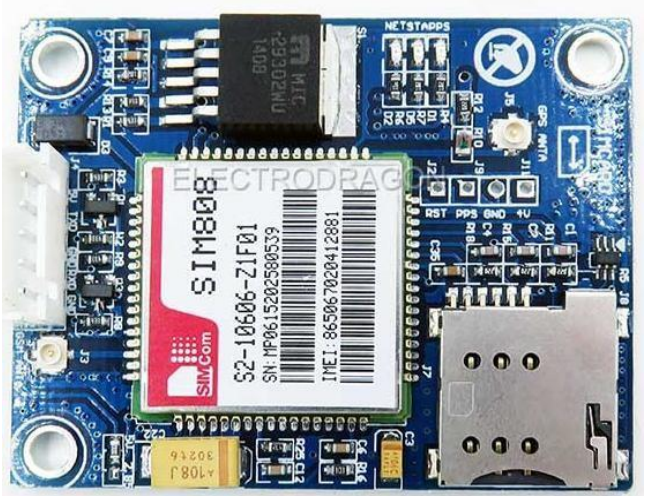

Fig3. Sim808 GSM module 
The general highlights of the GSM module incorporates a quad band of $850 / 900 / 1800 / 1900 \mathrm{MHz}$ and a GPRS multi-space class 12/10. It has a place with GPRS versatile station class B which is Compliant to GSM stage 2/2+ and Class 4 (2 W @ 850/900MHz) and Class (1 W @ 1800/1900MHz. It is likewise Bluetooth agreeable with 3.0+EDR. The FM extend is 76$109 \mathrm{MHz}$ overall groups which have a $50 \mathrm{KHz}$ tuning step. The elements of the module are $24 \times 24 \times 2.6 \mathrm{~mm}$, weighing $3.30 \mathrm{~g}$. It is constrained by AT orders which are 3GPP TS 27.007, 27.005 and SIMCOM improved AT Commands. The stockpile voltage ranges from $3.4-4.4 \mathrm{~V}$. The force utilization by the module is low. The working temperature ranges from $40^{\circ} \mathrm{C}-85^{\circ} \mathrm{C}$.

\section{SYSTEM DESIGN}

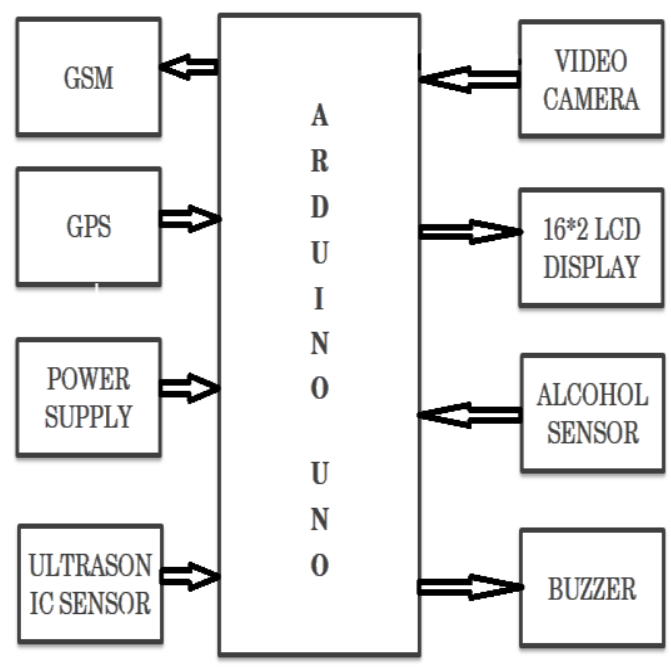

Fig 4. System Design

The Arduino Uno is interfaced with the GSM module utilizing two pins, pins 9 and 10, associated with the tx and rx pins of the module separately. The module is fuelled up by a different $5 \mathrm{~V}$ power supply. As referenced, the GSM reacts to AT orders which are sent to the module through the microcontroller by programming it utilizing the Arduino IDE. The GSM reacts to the AT orders continuously with a modest quantity of deferral of around 2-3 seconds relying upon the order sent. The GSM module has a yield support. Henceforth, when information is perused from the module the cradle gets cleared, which is the reason timing each order and perusing its reaction is basic to getting the necessary reaction. On the off chance that both these activities aren't done in a state of harmony, at that content is gotten by the module. The directions in particular scope and longitude can be gotten utilizing either GPS or GPRS. In this gadget, GPRS is utilized since it is substantially more dependable than GPS as GPS requires an open situation. Once
GPRS is actuated the directions are acquired utilizing the orders "AT+CIPGSMLOC $=1,1$ ". This additionally gives the current date and time alongside the directions. To start a call from the module the order "ATDxxxxxxxxxxx;" is utilized. The initiation of call mode turns on the amplifier information and speaker yield of the module. At the point when the necessary gadgets are associated with these ports in the correct arrangement, a client can banter with the beneficiary.

\section{B. LCD Arduino Interfacing}

The LCD has 16 interface pins [10] and is controlled up by the $5 \mathrm{~V}$ yield from the Arduino Uno. A resistor of $4.7 \mathrm{k}$ ohms controls the complexity of the LCD show. The read/compose pin is grounded since information is just to be composed onto the LCD. The register selected and empower pins are associated with advanced pins 6 and 8 individually. The LCD has 8 information sticks and can be worked in two modes, 8-piece mode and 4-piece mode. This gadget utilizes the LCD designed in the 4-piece mode. Information pins D4 to D7 are associated with advanced pins extending from 5 to 2 separately. The explanation behind including a LCD show is for it to go about as a gadget that prompts the condition of the gadget and show the consequences of the activities performed. The backdrop illumination control pin LED+ is associated with the $5 \mathrm{~V}$ yield of the Arduino and LED-is associated with the shared conviction.

\section{Working of Project}

In this paper there is a buzzer [13] when any woman press that button then the whole functioning will be start. All the components are connected to the Arduino uno and for the power supply (battery) also needful. The alcohol sensor will sense the alcohol concentration of the opposite person and the ultrasonic sensor sense the distance b/w woman and person. GPS will give the location of that place where the woman is in trouble. All the information like distance, location, alcohol concentration and "I am in trouble please help me" is send by the GSM in the message form to the registered number. The buzzer will produce the buzzer sound the woman press the button. [4,12] Message is sending or sent to the specific number this status will be shown on the LED and person who gets the message can be reach on that location easily by the help of their location.

\section{RESULTS AND DISCUSSIONS}

This segment talks about the consequences of the three methods of activity of the gadget and the potential incorporations to the gadget to improve its abilities. 


\section{A . Location Send mode}

As this mode is initiated by the press button, it takes 7 seconds to acquire the directions and messages are sent to the confided in contacts inside interims of 4 seconds. The message contains a hyperlink which coordinates the beneficiary straightforwardly to google maps where the area of beginning of the pain message will be shown.

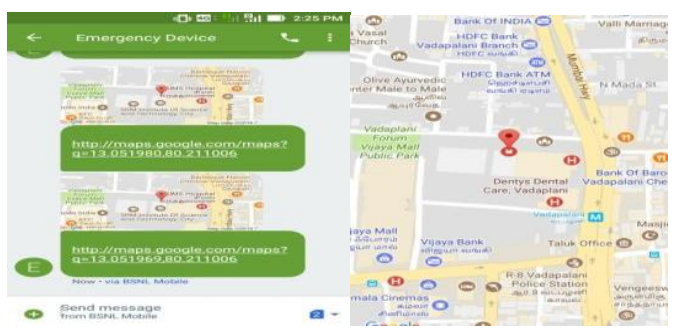

Fig 5. Device sends coordinates to recipient

\section{B. Outcome}

The device will be able to recognize the person from a range, its location and the face of the person with the help of a ultrasonic sensor (for range), GPS sensor (for location), and camera module (for capturing the face of person) [14]. Apart from this, the device will also check whether the person is alcoholic or non- alcoholic with the help of Alcohol sensor. All this information will be passed to the specific person's phone via GSM module.

\section{Future Scope}

- Attendance framework in instructive foundations and different spots.

- Bank Locker made sure about access.

- Ware houses and capacity places where IOT stock development is normal.

- Access Management.

- Tracking of products.

- Smart dust.

- Timing game.

\section{CONCLUSION}

Our essential objective of this venture is to guarantee each woman in our general public to provide a sense of security $[11,15]$. As indicated by the review in India 53\% of working women are not having a sense of security - Women is working in night in big cities (Bangalore-56\%, Chennai-28\%, Hyderabad-35\%, Mumbai26\%). It can assume a significant job by giving women a sheltered domain in all circumstances for instance (recognizing shrouded camera, physical compromised, irritated, theft, stalked). Actualizing constant application and a gadget, we can take care of the issues to a degree.

Acknowledgment: Authors are thankful for RTU, Kota as this work is done under the project sanction TEQIP-III/RTU (ATU)/CRS/2019-20/49, Borla: Bring on the real lady armor (Development of smart lady E-Wearable Security System for Women working in the field with location tracking system)

\section{REFERENCES}

[1] https://www.poverties.org/blog/violenceagainstwomen-in-india.

[2] https://en.wikipedia.org/wiki/Violence_ag ainst_women_in_India\#Sexual_crimes.

[3] Moodbiri Akash, Shahnasser Hamid,"Child Safety Wearable Device", 2017 International Conference on Information Networking (ICOIN).

[4] Chand D, Nayak S, Bhat KS, Par kh S. A mob le appl cat on for Women's Safety: WoS App. 2015 EEE Reg on 10 Conference TENCON; Macao. 2015 Nov 1-4. p. 1-5.

[5] E Hertzog Pierre and SwarArthur J t," Arduino - Enabling engineering students to obtain academic success in a designbased module.",2016 IEEE Global Engineering Education Conference (EDUCON).

[6] Abdullahi Badamasi Yusuf," The Working Principle Of An Arduino", Eletronics, Computer and Computation (ICECCO), 2014, 11th International Conference on Abuja, 2014 pp 1-4.

[7] https://coreelectronics.com.au/tutorials/ard uino-idetutorial.html.

[8] Bharavi U, Sukesh Rao M," Design and Development of GSM and GPS Tracking Module", 2017 2nd IEEE International Conference on Recent Trends in Electronics Information \& Communication Technology (RTEICT), May 19-20, 2017, India.

[9] Rychkov Dmitry, Alberto Ruy Altafim Pisani and Gerhard Reimund," Unipolar ferroelectrets - Following the example of the electret microphone more closely", 2014 Annual Report Conference on Electrical Insulation and Dielectric Phenomena.

[10] https://www.elecrow.com/download/SIM8 00\%20Series_AT\%20Command\%20Man ual_V1.09.pdf.

[11]Paradkar Abhijit, Sharma Deepak 'All in one Intelligent Safety System for Women Security'International Journal of Computer Applications, Volume 130 No.11, November2015 p.33-40 
International Journal of Engineering Applied Sciences and Technology, 2020

Vol. 5, Issue 2, ISSN No. 2455-2143, Pages 197-201

Published Online June 2020 in IJEAST (http://www.ijeast.com)

[12] Kiruthiga N, L. latha, S. Thangasamy Real Time Biometrics based Vehicle Security System with GPS and GSM Technology Procedia Computer Science 47 ( 2015 ) $471-479$

[13] Singhal Mudit and Singh Sudeep, An Embedded interface for GSM Based Car Secur ity System, int. Conference on Computational intellgence, Communication Systems and Networks, EEE Computer society, 2016.

[14] Yazdizadeha ,Ali, Pattersona Zachary, Farooqba Bilal 'An automated approach from GPS traces to complete trip information 'International Journal of TransportationScience and Technology ,Volume 8, Issue 1, March 2019, Pages 82-100

[15] Chand D, Nayak S, Bhat KS, Parikh S. A mobile application for Women's Safety: WoS

app.2015IEEEregion10ConferenceTENC ON; Macao. 2015 Nov 1-4. p. 1-5. 